\title{
Prospek Pengembangan Usahatani Kakao di Desa Pangsan, Kecamatan Petang, Kabupaten Badung
}

\author{
RISTA ULVIA RAMADHANI, I WAYAN BUDIASA, \\ A.A.A. WULANDIRA SAWITRI DJELANTIK
}

\author{
Program Studi Agribisnis, Fakultas Pertanian, Universitas Udayana \\ Jl. PB. Sudirman Denpasar 80323 \\ Email: ristaulvia@ymail.com \\ wba.agr@unud.ac.id
}

\begin{abstract}
Prospect of Cocoa Farming Development in Pangsan Village, Petang SubDistrict of Badung Regency
\end{abstract}

Cocoa plays an important role for the national economy, especially opening employment opportunities, sources of income, and foreign exchange. The objectives of this research are: to investigate the suitability of land for cocoa farming in Pangsan Village, financial feasibility of cocoa farming in Pangsan Village, seen from investment criteria, and market prospect of cocoa commodity of Pangsan Village production. The analysis used in this research is investment criteria method including $\mathrm{NPV}$, IRR, and Net B/C for financial feasibility analysis, while land suitability and market prospect are analyzed descriptively and qualitatively. The findings of the study showed that : land in Pangsan Village is appropriate (S2) for cocoa farming and it has low productivity compared to cocoa productivity in Bali and Indonesia, cocoa farming in Pangsan village which is intercropped with coconut and banana trees is financially feasible to be cultivated, with NPV of Rp 29.454.914,86, IRR of $38 \%$, and Net Benefit Cost Ratio (Net B/C) of 7,68, and the market prospect of cocoa products in Pangsan Village is not prospective for foodstuff, because the product of cocoa produced is not fermented and not certified.

Keywords: cocoa, development prospects, farming

\section{Pendahuluan}

\subsection{Latar Belakang}

Kakao merupakan salah satu komoditas perkebunan yang peranannya cukup penting bagi perekonomian nasional, khususnya sebagai penyedia lapangan kerja, sumber pendapatan dan devisa Negara. Kakao juga berperan dalam mendorong pengembangan wilayah dan pengembangan agroindustri (BPPMD Kaltimprov, 2009). Komoditi kakao sampai saat ini termasuk salah satu komoditi yang memiliki nilai ekonomis tinggi apabila dilihat dari prospek pasar yang cukup baik di pasar domestik dan pasar mancanegara.

Kabupaten Badung merupakan salah satu daerah di Provinsi Bali yang mengembangkan komoditi kakao. Kabupaten Badung memiliki tiga Kecamatan yang 
produktif dalam memproduksi kakao yaitu pada Kecamatan Mengwi, Kecamatan Abiansemal, dan Kecamatan Petang dapat dilihat pada tabel 1.

Tabel 1.

Luas Areal, Produksi, dan Produktivitas Perkebunan Kakao Rakyat di Kabupaten Badung 2015

\begin{tabular}{lccc}
\hline \multicolumn{1}{c}{ Kecamatan } & $\begin{array}{c}\text { Luas Areal TM } \\
(\mathrm{Ha})\end{array}$ & $\begin{array}{c}\text { Produksi } \\
(\text { Ton })\end{array}$ & $\begin{array}{c}\text { Produktivitas } \\
(\mathrm{Kg} / \mathrm{Ha} / \mathrm{Th})\end{array}$ \\
\hline Kec. Mengwi & 50,61 & 19,38 & 383 \\
Kec. Abiansemal & 210,97 & 138,40 & 656 \\
Kec. Petang & 54,77 & 23,77 & 434 \\
\hline \multicolumn{4}{c}{} \\
\hline Keterangan. TM yaitu Tanaman Menghasilkan
\end{tabular}

Keterangan : TM yaitu Tanaman Menghasilkan

Sumber : Dinas Perkebunan Provinsi Bali, 2015.

Pada tabel 1 Kecamatan Petang diketahui memiliki produktivitas di bawah rata-rata produktivitas Kabupaten Badung yaitu sebesar $434 \mathrm{~kg} / \mathrm{ha} / \mathrm{th}$. Berdasarkan hal tersebut Kecamatan Petang perlu melakukan pengembangan dalam usahatani kakao agar mencapai produktivitas yang optimal.

Desa Pangsan memiliki potensi dalam mengembangkan usahatani kakao, namun belum berperan secara optimal karena produktivitasnya yang masih rendah, hal itu tidak terlepas dari kesesuian lahan yang cocok untuk pengembangan usahatani kakao agar mencapai produktivitas yang optimal, di samping itu petani belum mengetahui berapa besar manfaat dan keuntungan secara finansial dari usahatani kakao. Kurangnya lembaga pemasaran yang menaungi hasil produksi kakao di Desa Pangsan mempengaruhi prospektif produk kakao yang di produksi. Berdasarkan keadaan di atas penulis tertarik untuk melakukan penelitian mengenai Prospek Pengembangan Usahatani Kakao di Desa Pangsan, Kecamatan Petang, Kabupaten Badung.

\subsection{Rumusan Masalah}

Berdasarkan latar belakang di atas, maka rumusan masalah penelitian dapat dirumuskan sebagai berikut.

1. Bagaimana kesesuaian lahan dan produktivitas usahatani kakao di Desa Pangsan, Kecamatan Petang, Kabupaten Badung?

2. Bagaimana kelayakan finansial usahatani kakao di Desa Pangsan, Kecamatan Petang, Kabupaten Badung dilihat dari kriteria investasi yaitu NPV, IRR, dan Net $\mathrm{B} / \mathrm{C}$ ?

3. Bagaimana prospek pasar komoditas kakao produksi Desa Pangsan, Kecamatan Petang, Kabupaten Badung? 


\subsection{Tujuan Penelitian}

Tujuan dari penelitian ini adalah untuk mengetahui hal-hal sebagai berikut.

1. Kesesuaian lahan dan produktivitas usahatani kakao di Desa Pangsan, Kecamatan Petang, Kabupaten Badung.

2. Kelayakan finansial usahatani kakao di Desa Pangsan, Kecamatan Petang, Kabupaten Badung dilihat dari kriteria investasi yaitu NPV, IRR, dan Net B/C.

3. Prospek pasar komoditas kakao produksi Desa Pangsan, Kecamatan Petang, Kabupaten Badung.

\section{Metodologi Penelitian}

\subsection{Lokasi dan Waktu Penelitian}

Penelitian ini dilaksanakan di Desa Pangsan, Kecamatan Petang, Kabupaten Badung, dari awal bulan Februari hingga akhir Februari 2017. Pemilihan lokasi dilakukan secara sengaja (purposive), dengan pertimbangan bahwa komoditi kakao di Desa Pangsan merupakan komoditi unggulan yang produksinya cukup besar dan memiliki jumlah KK petani terbanyak yang berusahatani kakao di Kecamatan Petang.

\subsection{Metode Pengumpulan Data}

Metode pengumpulan data yang digunakan pada penelitian ini adalah metode survey. Metode survey merupakan penelitian yang mengambil sampel dari satu populasi dengan menggunakan kuisioner sebagai alat pengumpulan data yang pokok. Pada metode survey ini peneliti mengedarkan kuisioner, yang berisikan daftar pertanyaan kepada responden mengenai data yang terkait dengan penelitian.

\subsection{Penentuan Populasi dan Sampel}

Populasi dalam penelitian ini adalah para petani yang melakukan usahatani kakao di Desa Pangsan sebanyak 138 orang petani yang tersebar di tiga subak Abian yaitu Subak Abian Dhana Asih, Subak Abian Kembang Sari, dan Subak Abian Nata Nugraha.

Menurut Sujarweni (2014), sampel adalah bagian dari sejumlah karakteristik yang dimiliki oleh populasi yang digunakan untuk penelitian. Besaran sampel dalam penelitian ini ditentukan berdasarkan rumus slovin dari Indrawan \& Yaniawati (2014) sebagai berikut:

$$
\begin{gathered}
\mathrm{n}=\frac{\mathrm{N}}{\left(1+\mathrm{N}(\mathrm{d})^{2}\right)} \\
\mathrm{n}=\frac{138}{\left(1+138(0.15)^{2}\right)} \\
\mathrm{n}=33,6 \text { dibulatkan menjadi 34 orang }
\end{gathered}
$$

Keterangan :

$\mathrm{n}=$ Besar sampel

$\mathrm{N}=$ Besar populasi

$\mathrm{d}$ = Tingkat kepercayaan / ketepatan yang diinginkan 
Teknik sampling yang digunakan dalam penelitian ini adalah proportional random sampling, dengan besaran sampel yang diperoleh sebanyak 34 orang. Menentukan responden pada masing-masing subak dilakukan secara acak, dengan menggunakan sistem undian.

\subsection{Penentuan Informan Kunci}

Informan kunci pada penelitian ini adalah orang yang mengetahui keadaan dan permasalahan yang berkaitan dengan penelitian ini pada lokasi penelitian. Data yang diperlukan adalah mengenai data proyeksi produksi dan data saluran pemasaran. Data proyeksi produksi diperoleh dari informan kuci UML di Slemadeg Timur yaitu Bapak Made Gunawan, sedangkan data saluran pemasaran diperoleh dari para pedagang di pasar Petang, dan Manajer di Perusahaan Pengolah Coklat yaitu Bapak Topan Ardiansyah.

\subsection{Metode Analisis}

\subsubsection{Kesesuaian lahan}

Data yang diperoleh untuk kesesuaian lahan dibahas secara deskriptif yang dilihat dari kriteria lahan yang cocok bagi tanaman kakao kemudian dibandingkan dengan keadaan di lokasi penelitian dan juga melihat produktivitas tanaman kakao di Desa Pangsan, Kecamatan Petang, Kabupaten Badung. Kriteria teknis kesesuaian lahan untuk kakao dapat dilihat pada tabel 2. 
Tabel 2.

Kriteria Teknis Kesesuaian Lahan untuk Kakao

\begin{tabular}{|c|c|c|c|c|c|}
\hline \multirow[t]{2}{*}{ No } & \multirow[t]{2}{*}{ Karakter } & \multicolumn{4}{|c|}{ Kelas Kesesuaian Lahan } \\
\hline & & S1 & S2 & S3 & $\mathrm{N}$ \\
\hline \multirow[t]{7}{*}{1} & c- Iklim & & & & \\
\hline & Curah Hujan Tahunan (mm) & 1.500 & 1.250 & $1.100-$ & $<1.100$ \\
\hline & & 2.000 & 1.500 & 1250 & \\
\hline & & & 2.500 & $3.000-4.000$ & $>4.00$ \\
\hline & & & 3.000 & & \\
\hline & Lama Bulan Kering $(<60$ & $0-1$ & $1-3$ & $3-5$ & $>5$ \\
\hline & $\mathrm{mm} / \mathrm{bl})$ & & & $1-2$ & $<1$ \\
\hline \multirow[t]{3}{*}{2} & t-Elevasi (m dpl) & & & & \\
\hline & Kakao Mulia & $0-600$ & $600-700$ & $700-800$ & $>800$ \\
\hline & Kakao Lindak & $0-300$ & $300-450$ & $450-600$ & $>600$ \\
\hline 3 & s-Lereng (\%) & $0-8$ & $8-15$ & $15-45$ & $>45$ \\
\hline \multirow[t]{7}{*}{4} & r-Sifat fisik tanah & & & & \\
\hline & Kedalaman efektif $(\mathrm{cm})$ & $>150$ & $100-150$ & $600-100$ & $<60$ \\
\hline & Tekstur & $\begin{array}{l}\text { Lempung } \\
\text { berpasir }\end{array}$ & $\begin{array}{l}\text { Pasir } \\
\text { Berlempung }\end{array}$ & Liat & Pasir \\
\hline & & $\begin{array}{l}\text { Lempung } \\
\text { berliat }\end{array}$ & $\begin{array}{l}\text { Liat } \\
\text { Berpasir }\end{array}$ & & Liat Berat \\
\hline & & $\begin{array}{l}\text { Lempung } \\
\text { berdebu } \\
\text { Lempung } \\
\text { liat berdebu }\end{array}$ & $\begin{array}{l}\text { Liat } \\
\text { Berdebu }\end{array}$ & & \\
\hline & Batu di permukaan (\%) & - & $0-3$ & $3-15$ & $>15$ \\
\hline & d- Genangan & - & - & $1-7$ hari & $>7$ hari \\
\hline \multirow[t]{3}{*}{5} & Klas drainase & Baik & Agak Baik & $\begin{array}{l}\text { Agak Buruk } \\
\text { Buruk }\end{array}$ & $\begin{array}{l}\text { Berlebihan } \\
\text { sangat } \\
\text { Buruk }\end{array}$ \\
\hline & & & & Agak & \\
\hline & & & & Berlebihan & \\
\hline \multirow[t]{10}{*}{6} & n-Sifat kimia tanah ( 0-30) & & & & \\
\hline & $\mathrm{Ph}$ & $6,0-7,0$ & $5,0-6,0$ & $4,0-5,0$ & $>8,0$ \\
\hline & & & $7,0-7,5$ & $7,5-8,0$ & $<4,0$ \\
\hline & C - Organik (\%) & $2-5$ & $1-2$ & $0,5-1$ & $<0,5$ \\
\hline & & & $5-10$ & $10-15$ & $>15$ \\
\hline & KPK (me/100 g) & $>15$ & $10-15$ & 5- 10 & $<5$ \\
\hline & $\mathrm{KB}(\%)$ & $>35$ & $20-35$ & $<20$ & - \\
\hline & $\mathrm{N}(\%)$ & $>0.21$ & $0.1-0.2$ & $<0.1$ & - \\
\hline & $\mathrm{P} 2 \mathrm{O} 5$ tersedia (ppm) & $>16$ & $10-15$ & $<10$ & - \\
\hline & Kdd (me \%) & $>0.3$ & $0.1-0.3$ & $<0.1$ & - \\
\hline \multirow[t]{3}{*}{7} & $\mathrm{x}$-Toksitas & & & & \\
\hline & Salinitas (mm hos/cm) & $<1$ & $1-3$ & $3-4$ & $>4$ \\
\hline & Kejenuhan AI (\%) & $<5$ & $5-20$ & $20-60$ & $>60$ \\
\hline
\end{tabular}

Keterangan :

$\mathrm{S} 1=$ sangat sesuai

$\mathrm{S} 2$ = sesuai

S3 = sesuai marginal

$\mathrm{N}=$ tidak sesuai

Sumber : Ditjenbun Pertanian 2014

\subsubsection{Kelayakan usahatani}

Data yang berhubungan dengan kelayakan usahatani kakao ini dianalisis dengan metode analisis kuantitatif dengan mengunakan kriteria investasi yaitu 
metode Net Present Value (NPV), Internal Rate of Return (IRR), dan Net Benefit Cost Ratio (Net B/C).

\section{Net Present Value (NPV)}

Net Present Value (NPV) adalah nilai sekarang dari keuntungan bersih (manfaat neto tambahan) yang akan diperoleh pada masa mendatang, merupakan selisih antara nilai sekarang arus manfaat dikurangi dengan nilai sekarang arus biaya (Gittinger, 1986).

$$
\mathrm{NPV}=\sum_{\mathrm{t}=1}^{\mathrm{t}=\mathrm{n}} \frac{\mathrm{Bt}-\mathrm{Ct}}{(1+\mathrm{i})^{1}}
$$

Dimana :

$\mathrm{Bt} \quad=$ manfaat yang diperoleh setiap tahun dari proyek.

$\mathrm{Ct} \quad=$ biaya yang dikeluarkan setiap tahun dari proyek.

$\mathrm{n} \quad=$ jumlah tahun dalam proyek

$\mathrm{i} \quad=$ tingkat bunga (diskonto)

Kriteria penilaian untuk Net Present Value (NPV) adalah sebagai berikut :

a. NPV $>0$, maka usaha dinyatakan layak (feasible).

b. NPV <0, maka usaha dinyatakan tidak layak (no feasible).

c. NPV $=0$, maka usaha dinyatakan dalam posisi Break Event Point (BEP).

\section{Internal Rate of Return (IRR)}

Internal Rate of Returns (IRR) adalah tingkat diskonto yang membuat nilai bersih sekarang (NPV) dari arus kas sama dengan nol.

IRR adalah bahwa tingkat diskonto 'i' sehingga

$$
\operatorname{IRR}=\sum_{\mathrm{t}-1}^{\mathrm{n}} \frac{\mathrm{Bn}-\mathrm{Cn}}{(1+\mathrm{i})^{\mathrm{n}}}=0 \text { i.e NPV }=0 .
$$

Dimana

$$
\begin{array}{ll}
\mathrm{Bn} & =\text { manfaat yang diperoleh setiap tahun dari proyek. } \\
\mathrm{Cn} & =\text { biaya yang dikeluarkan setiap tahun dari proyek. } \\
\mathrm{n} & =\text { jumlah tahun dalam proyek. } \\
\mathrm{i} & =\text { tingkat bunga (diskonto). }
\end{array}
$$

Kriteria penilaian untuk Internal Rate of Returns (IRR) adalah sebagai berikut:

a. Jika IRR > discount rate, berarti usaha layak dilaksanakan.

b. Jika IRR < discount rate, berarti usaha tidak layak dilaksanakan.

d. Jika IRR = discount rate, berarti usaha dinyatakan dalam posisi Break Event Point (BEP).

\section{Net Benefit Cost Ratio (Net $\mathrm{B} / \mathrm{C})$}

Net $\mathrm{B} / \mathrm{C}$ adalah perbandingan antara jumlah NPV positif dengan jumlah NPV negative. Net $\mathrm{B} / \mathrm{C}$ ini menunjukkan gambaran berapa kali lipat benefit akan diperoleh dari cost yang dikeluarkan (Abdul Choliq, 1999).

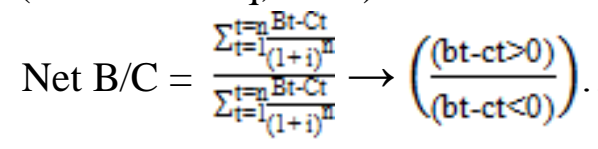

Dimana :

Bt = penerimaan pada tahun ke 1 sampai dengan tahun ke $n$

$\mathrm{Ct} \quad=$ pengeluaran pada tahun ke 1 sampai dengan ke $\mathrm{n}$. 
$\mathrm{n} \quad=$ jumlah tahun dalam proyek

$\mathrm{i}=$ tingkat discount rate

Bila nilai Net $\mathrm{B} / \mathrm{C}>1$ maka proyek tersebut layak,jika Net $\mathrm{B} / \mathrm{C}<1$ maka proyek tersebut tidak layak, dan jika Net $\mathrm{B} / \mathrm{C}=1$ maka proyek tersebut dinyatakan dalam posisi Break Event Point (BEP).

\subsubsection{Prospek pasar}

Prospek pasar dianalisis secara deskriptif, dimana data yang diperoleh berhubungan dengan pemasaran kakao di Desa Pangsan. Hal-hal yang terkait dengan prospek pasar ini yaitu mengenai bagaimana saluran pemasaran kakao di Desa Pangsan, dan dimana saja tempat penjualan kakao dilakukan. Kriteria dari prospek pasar ini dilihat dari jumlah maksimum produk yang diproduksi, kualitas produk yang diminta oleh pasar, dan harga komoditi kakao yang prospektif.

\section{Hasil dan Pembahasan}

\subsection{Kesesuaian Lahan}

Kesesuaian lahan di Desa Pangsan tergolong kelas S2 (sesuai) untuk komoditi kakao, berdasarkan perbandingan data topografi Desa Pangsan dengan tabel 2 kriteria teknis kesesuaian lahan kakao. Hal tersebut dilihat dari rata-rata curah hujan yaitu $2000-7000 \mathrm{~mm} / \mathrm{th}$, suhu udara rata-rata $28^{\circ} \mathrm{C}$, dan jenis tanah di Desa Pangsan berjenis tanah andosol berwarna coklat, kaya akan zat organik, beremahremah, bertekstur medium serta jarang (Desa Pangsan, 2006).

Produktivitas komoditi kakao di Desa Pangsan tergolong rendah, apabila dibandingkan dengan produktivitas kakao di Provinsi Bali dan Indonesia. Produktivitas rata-rata kakao di Provinsi Bali yaitu 572,80 kg/ha/th biji kakao kering, produktivitas rata-rata kakao di Indonesia yaitu $819,40 \mathrm{~kg} / \mathrm{ha} /$ th biji kakao kering, sedangkan di Desa Pangsan produktivitas rata-rata komoditi kakao sebesar 392,04 $\mathrm{kg} / \mathrm{ha} / \mathrm{th}$ biji kakao kering. Rendahnya produktivitas kakao di Desa Pangsan disebabkan oleh luas lahan dan jumlah pohon kakao yang tidak sebanding. Satu hektar luas lahan seharusnya terdapat 1.100 pohon kakao dengan jarak tanam 3 x 3 meter, namun di Desa Pangsan hanya terdapat 216 pohon kakao per hektar. Tanaman kakao di Desa Pangsan yang ditumpangsarikan dengan tanaman pisang dan kelapa, seharusnya petani di Desa Pangsan dapat menanam 767 pohon kakao per hektar. Namun di Desa Pangsan hal tersebut belum dapat tercapai, maka hal inilah yang menyebabkan rendahnya produktivitas kakao di Desa Pangsan.

\subsection{Kelayakan Finansial}

\subsubsection{Net present value (NPV)}

Perhitungan Net Present Value (NPV) usahatani kakao di Desa Pangsan dengan discount factor sebesar $9 \%$ adalah Rp 29.454.914,86. Hasil perhitungan ini menunjukkan bahwa usahatani kakao di Desa Pangsan layak untuk dilaksanakan karena nilai NPV yang dihasilkan bernilai positif. Hasil nilai kriteria investasi dapat dilihat pada tabel 3 . 
Tabel 3.

Nilai Kriteria Investasi Usahatani Kakao di Desa Pangsan

\begin{tabular}{ccc}
\hline No & Kriteria Investasi & Nilai \\
\hline 1 & NPV & Rp. 29.454.914,86 \\
2 & IRR & $38 \%$ \\
3 & Net B/C & 7,68 kali \\
\hline
\end{tabular}

Sumber: Data primer diolah (2017)

\subsubsection{Internal rate of return (IRR)}

Berdasarkan hasil perhitungan dengan discount factor $9 \%$ per tahun, maka diperoleh IRR sebesar 38\%. Hasil penelitian ini berarti bahwa proyek usahatani kakao layak untuk dilaksanakan karena nilai IRR lebih besar dari tingkat bunga yang berlaku saat ini yaitu sebesar $9 \%$.

\subsubsection{Net benefit cost ratio (Net $\mathrm{B} / \mathrm{C})$}

Berdasarkan hasil perhitungan Net B/C dengan tingkat bunga $9 \%$ adalah sebesar 7,68, yang berarti bahwa usahatani kakao di Desa Pangsan layak untuk dikembangkan karena nilai $\mathrm{Net} \mathrm{B} / \mathrm{C}>1$. Nilai ini berarti bahwa setiap Rp 1,00 yang dikeluarkan oleh petani akan menghasilkan benefit (keuntungan) sebesar 7,68 kali.

\subsection{Prospek Pasar}

Prospek pasar usahatani kakao di Desa Pangsan dilihat dari saluran pemasarannya. Berdasarkan hasil penelitian, saluran pemasaran kakao dari petani ke konsumen akhir di Desa Pangsan, Kecamatan Petang terdapat satu saluran pemasaran. Saluran pemasaran komoditi kakao di Desa Pangsan dapat dilihat pada gambar 1.

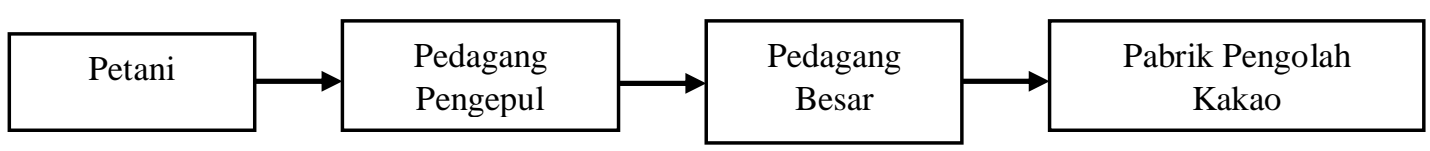

Gambar 1.

Saluran Pemasaran Kakao di Desa Pangsan

Pada gambar 1 menunjukkan bahwa petani kakao di Desa Pangsan memasarkan produknya ke pedagang pengepul yang ada di pasar Petang. Terdapat tiga pedagang pengepul di Pasar Petang. Pedagang pengepul tersebut ada yang menjual produknya ke pedagang besar di Singaraja yaitu BT. Cocoa dan ada juga yang menjual ke pedagang besar di Negara yaitu Cargill. Produk kakao dari pedagang besar akan di bawa ke gudang sementara apabila jumlahnya kurang dari 13 ton, sedangkan jika produk kakao yang terkumpul melebihi 13 ton maka produk kakao akan dibawa langsung ke pabrik pengolah coklat di BT. Cocoa Tangerang dan Cargill Gresik. Pabrik pengolah kakao BT. Cocoa mengambil biji kakao di Bali sebanyak 2.400 ton/th dengan kapasitas produksi perusahaan sebesar 40.000 ton/th. 
Desa Pangsan menghasilkan produk biji kakao asalan dengan jumlah produksi $470,45 \mathrm{~kg} / \mathrm{th}$. Berdasarkan hal tersebut, dapat dikatakan bahwa Desa Pangsan hanya mampu memenuhi sebesar 5,10\% produk kakao yang diminta BT. Cocoa dari total pengambilan biji kakao di Bali.

Produk kakao yang dihasilkan oleh petani di Desa Pangsan adalah produk kakao non fermentasi. Hal tersebut dikarenakan petani membutuhkan penghasilan yang cepat sehingga petani tidak memfermentasikan produknya. Mutu kakao yang dihasilkan yaitu 104 per 100 gram, namun mutu tersebut belum tersertifikasi. Produk kakao yang tidak fermentasi diolah menjadi bahan baku kosmetik di pabrik BT. Cocoa, sedangkan untuk bahan pangan perusahaan meminta kakao yang fermentasi. Berdasarkan hal tersebut, dapat dikatakan bahwa produk kakao di Desa Pangsan tidak prospektif untuk bahan pangan, namun prospektif untuk bahan non pangan. Data untuk pabrik pengolah kakao di Cargill tidak tersedia, sehingga hanya menggunakan data dari pabrik pengolah kakao BT. Cocoa. Kakao dijual ke pasar (pedagang pengepul) dengan rata-rata harga $\mathrm{Rp} 23.250 / \mathrm{kg}$.

\section{Kesimpulan dan Saran}

\subsection{Kesimpulan}

Berdasarkan pemaparan di atas adapun kesimpulan yang diperoleh adalah sebagai berikut. Lahan di Desa Pangsan tergolong sesuai (S2) untuk usahatani kakao, karena dilihat dari kriteria teknis kesesuaian lahan untuk kakao yaitu curah hujan, suhu, dan jenis tanah. Produk kakao di Desa Pangsan memiliki produktivitas yang rendah jika dibandingkan dengan produktivitas kakao di Bali dan Indonesia, usahatani kakao di Desa Pangsan yang ditumpangsarikan dengan kelapa dan pisang layak secara finansial untuk diusahakan, dengan NPV yang diperoleh sebesar Rp 29.454.914,86, IRR lebih besar dari discount rate yaitu sebesar 38\%, dan Net Benefit Cost Ratio (Net B/C) yaitu sebesar 7,68 kali, dan prospek pasar produk kakao di Desa Pangsan tidak prospektif untuk bahan pangan karena produk yang dihasilkan adalah kakao asalan yang tidak difermenasi dan tidak bersertifikasi.

\subsection{Saran}

Berdasarkan penelitian yang dilakukan adapun saran yang diajukan penulis yaitu sebagai berikut : petani kakao di Desa Pangsan diharapkan untuk meningkatkan populasi tanaman kakao per hektarnya minimal dua sampai tiga kali lipat dari jumlah pohon saat ini yaitu 216 pohon per hektar, petani diharapkan dapat memfermentasikan produk kakao yang dihasilkan agar dapat prospektif dan mampu meningkatkan nilai jual, dan peneliti lain diharapkan mampu menganalisis kesesuaian lahan di Desa Pangsan secara lengkap. 


\section{Ucapan Terimakasih}

Penulis mengucapkan terimakasih kepada seluruh pihak yang telah membantu penulis dalam melaksanakan penelitian sehingga karya ilmiah ini dapat dipublikasikan pada e-jurnal.

\section{Daftar Pustaka}

Abdul Choliq, Rivai Wirasasmita, \& Sumarna Hasan. 1999. Evaluasi Proyek. Edisi Revisi. Pionir Jaya. Bandung.

BPPMD (Badan Perijinan dan Penanaman Modal Daerah) Provinsi Kalimantan Timur. 2009. Prospek Menggiurkan Investasi Budidaya Kakao. http://bppmd.kaltimprov.go.id (diunduh 17 November 2016).

Dinas Perkebunan Provinsi Bali. 2015. Statistik Perkebunan Bali 2015. Denpasar : Dinas Perkebunan Provinsi Bali.

Direktorat Jenderal Perkebunan. 2015. Statistik Perkebunan Indonesia Komoditas Kakao 2014 - 2016. http://ditjenbun.pertanian.go.id (diunduh 20 Desember 2016).

Desa Pangsan. 2016. Keadaan Perkebunan Kakao. http.//pangsanbali.blogspot.com/ (diunduh 30 Januari 2017).

Desa Pangsan. 2016. Monografi Desa dan Kelurahan Desa Pangsan. Badung.

Gittinger, J. Price. 1986. Analisa Ekonomi Proyek-proyek Pertanian. Edisi Kedua. UI Press. Jakarta.

Indrawan \& Yaniawati. 2014. Metodologi Penelitian Kuantitatif, Kualitatif, dan Campuran untuk Manajemen, Pembangunan, dan Pendidikan. Edisi Revisi. PT. Refika Aditama. Bandung.

Sujarweni, Wiratna V. 2014. Metodologi Penelitian. Yogyakarta : Pustaka Baru Press.

UPTD (Unit Pelaksana Teknis Daerah) Kecamatan Petang. 2016. Luas Areal dan Produksi Komoditi Perkebunan Kakao Triwulan Dua Tahun 2016. 